\title{
LA DEMANDA Y LA CONTESTACIÓN EN EL ARBITRAJE
}

\author{
Mario Castillo Freyre ${ }^{1}$ \\ Rita Sabroso Minaya ${ }^{2}$ \\ Jhoel Chipana Catalán ${ }^{3}$
}

\section{RESUMEN}

A través del presente artículo, los autores estudian figuras como la demanda, la contestación, la reconvención, la posibilidad de ampliar cada una de éstas, la acumulación, entre otras. No debe perderse de vista el aspecto crítico que este ensayo posee, pues, como se verá, aparentemente el tratamiento que la Ley de Arbitraje peruana les ha otorgado a algunas de las figuras mencionadas no ha sido el más idóneo.

\section{PALABRAS CLAVE}

Arbitraje. Demanda. Contestación. Medios probatorios. Modificación. Ampliación. Acumulación. Consolidación.

\section{ABSTRACT}

In this Article, the authors examine different institutions such as lawsuits, answers, counterclaim, the possibility of extending each of these, consolidation, among others. We must not lose sight of the critical aspect this essay addresses: apparently, the way the Peruvian Arbitration Law has not dealt with some of such institutions in the most appropriate manner, as we will see.

\section{KEY WORDS}

Arbitration. Lawsuit. Answer. Means of evidence. Amendment. Extension. Consolidation.

\section{INTRODUCCIÓN}

Entre los diversos temas contenidos en la ley que regula la materia arbitral en nuestro país, se encuentra aquél referido a la demanda y la contestación de ésta al interior de un proceso arbitral. Esta materia es abordada por la Ley de Arbitraje peruana (Decreto Legislativo n. $^{\circ}$ 1071 , vigente desde el 1 de septiembre del año 2008), a través de su artículo 39, el cual, a la letra, señala:
Artículo 39.- «Demanda y contestación

1. Dentro del plazo convenido por las partes o determinado por el tribunal arbitral y a menos que las partes hayan acordado algo distinto respecto del contenido de la demanda y de la contestación, el demandante deberá alegar los hechos en que se funda, la naturaleza y las circunstancias de la controversia y las pretensiones que formula y el demandado deberá establecer su posición respecto a lo planteado en la demanda.

2. Las partes, al plantear su demanda y contestación, deberán aportar todos los documentos que consideren pertinentes 0 hacer referencia a los

1 Mario Castillo Freyre, Magíster y Doctor en Derecho. Abogado en ejercicio, socio del Estudio que lleva su nombre. Miembro de Número de la Academia Peruana de Derecho; profesor principal de Obligaciones y Contratos en la Pontificia Universidad Católica del Perú y en la Universidad Femenina del Sagrado Corazón. Catedrático de las mismas materias y de Arbitrajes Especiales en la Universidad de Lima. Director de las colecciones Biblioteca de Arbitraje y Biblioteca de Derecho de su Estudio. www.castillofreyre.com.

2 Rita Sabroso Minaya, Abogada por la Pontificia Universidad Católica del Perú, con estudios en la Maestría en Derecho de la Propiedad Intelectual y de la Competencia en la misma Casa de Estudios. Profesora de Derecho de las Obligaciones y Arbitrajes Especiales en las Facultades de Derecho de la Pontificia Universidad Católica del Perú y de la Universidad de Lima, respectivamente. Miembro del área de Arbitraje del Estudio Mario Castillo Freyre.

3 Jhoel Chipana Catalán. Abogado por la Pontificia Universidad Católica del Perú. Adjunto de Cátedra en la misma casa de estudios y Abogado en el Estudio Mario Castillo Freyre. 
documentos $\mathrm{u}$ otras pruebas que vayan a presentar o proponer.

3. Salvo acuerdo en contrario, en el curso de las actuaciones, cualquiera de las partes podrá modificar o ampliar su demanda o contestación, a menos que el tribunal arbitral considere que no corresponde permitir esa modificación en razón de la demora con que se hubiere hecho, el perjuicio que pudiera causar a la otra parte o cualesquiera otras circunstancias. El contenido de la modificación y de la ampliación de la demanda o contestación, deberán estar incluidos dentro de los alcances del convenio arbitral.

4. Salvo pacto en contrario, el tribunal arbitral no puede disponer la consolidación de dos o más arbitrajes, o disponer la realización de audiencias conjuntas.»

Cabe señalar que este precepto concuerda, por ejemplo, con la Ley Modelo UNCITRAL de arbitraje comercial internacional (artículo 23), así como con la Ley de Arbitraje española del año 2003 (artículo 29).
Asimismo, no debemos dejar de mencionar que este tema, dentro de la normativa nacional, tiene como antecedente inmediato al numeral 112 de la derogada Ley General de Arbitraje del año 1996, Ley n. ${ }^{\circ} 26572 .{ }^{4}$

Con estas precisiones claras, en adelante se presentará el análisis de este tema tan importante.

\section{DEMANDA Y CONTESTACIÓN}

El inciso 1 del artículo 39 de nuestra Ley de Arbitraje, establece que dentro del plazo convenido por las partes o determinado por el tribunal arbitral y a menos que las partes hayan acordado algo distinto respecto del contenido de la demanda y de la contestación, el demandante deberá alegar los hechos en que se funda, la naturaleza y las circunstancias de la controversia y las pretensiones que formula, y el demandado deberá establecer su posición respecto a lo planteado en la demanda.

Para entender de manera clara los alcances y limitaciones de los conceptos de demanda y contestación, citaremos algunas definiciones que realizan una serie de procesalistas sobre algunos conceptos básicos (de más está decir que dichos conceptos son de aplicación mutatis mutandis al ámbito arbitral).
En ese entender, en principio, resulta necesario iniciar el análisis del tema desarrollando qué se entiende por «pretensión material» y qué por «pretensión procesal».

Monroy Gálvez ${ }^{5}$ señala que al ser abstracto, el derecho de acción carece de existencia material: es sólo un impulso de exigir tutela jurisdiccional. Sin embargo, es cierto también que realizamos tal actividad cuando tenemos una exigencia material y concreta respecto de otra persona o de otro sujeto de derecho. El acto de exigir algo a otro -que debe tener por cierto la calidad de caso justiciable, es decir, relevancia jurídica-, antes del inicio de un proceso se denomina pretensión material, la cual no es necesariamente el punto de partida de un proceso. Sin embargo, cuando la pretensión material no es satisfecha y el titular de ésta carece de alternativas extrajudiciales para exigir o lograr que tal hecho ocurra, el titular de la pretensión material la puede convertir en pretensión procesal, que no es otra cosa que la manifestación de un sujeto de derecho que exige algo a otro a través de un órgano especializado en la solución de conflictos.

A su vez, continúa el citado profesor, siendo la pretensión procesal el núcleo de la demanda $y$, en consecuencia, el elemento central de la relación procesal,

4 Artículo 112.- «Demanda y contestación

Dentro del plazo convenido por las partes o determinado por el tribunal arbitral, el demandante deberá alegar los hechos en que se funda la demanda, los puntos controvertidos y el objeto de la demanda, y el demandado deberá responder los extremos alegados en la demanda, a menos que las partes hayan acordado otra cosa respecto de los elementos que la demanda y la contestación deban necesariamente contener. Las partes podrán aportar, al formular sus alegaciones, todos los documentos que consideren pertinentes o hacer referencia a los documentos u otras pruebas que vayan a presentar. Salvo pacto en contrario de las partes, en el curso de las actuaciones cualquiera de las partes podrá modificar o ampliar su demanda o contestación, a menos que el tribunal arbitral considere improcedente esa alteración en razón con la demora en que se ha hecho.»

5 Cfr. Monroy Gálvez, Juan. Teoría general del proceso. Lima: Palestra, 2007, pp. 500 y ss. 
resulta necesario determinar qué elementos la conforman. Así, ésta debe contener una fundamentación jurídica, es decir, un derecho subjetivo que sustente el reclamo. Por otro lado, la pretensión procesal debe sustentarse en la ocurrencia de cierto número de hechos cuya acreditación posterior a través de la actividad probatoria permitirá que la pretensión contenida en la demanda sea declarada fundada; esto último se denomina fundamentos de hecho. Estos dos elementos de manera conjunta reciben el nombre de causa petendi, iuris petitum o iuris petitio.

Finalmente, la pretensión procesal, dice Monroy, tiene un elemento central, éste es el pedido concreto, es decir, aquello que en el campo de la realidad es lo que el pretensor quiere sea una actuación del pretendido. Este elemento recibe el nombre de petitorio, aun cuando la doctrina suele también llamarle petitum o petitio.

Ahora bien, todo lo señalado requiere de una expresión concreta. Ella se da, pues, a través de la demanda.

Chiovenda ${ }^{6}$ señala que la demanda es el acto con el que la parte (actora), afirmando la existencia de una voluntad concreta de la ley que le garantiza un bien, declara la voluntad de que la ley sea actuada frente a otra parte (demandado), e invoca para este fin la autoridad.

Del otro lado, la contestación de la demanda tiene como nú- cleo el derecho de contradicción. González Pérez ${ }^{7}$ aborda el tema desde un punto de vista totalizador, al poner énfasis en el carácter constitucional de dicha garantía. Así, señala que este derecho fundamental hoy constitucionalizado, y como tal extendible, es de necesario reconocimiento en las leyes procesales en cualquier clase de procedimiento, con mayor o menor alcance, según su naturaleza o finalidad.

En un escenario infraconstitucional, Devis Echeandía ${ }^{8}$ señala que el derecho de contradicción, lo mismo que el de acción, pertenece a toda persona natural o jurídica, y tanto su causa como su fin están constituidos por un interés que consiste en el derecho de obtener la decisión del conflicto que se le plantea al demandado mediante la sentencia que el órgano jurisdiccional debe dictar. Principalmente contempla la defensa de dos principios fundamentales para la organización social, como son el que prohíbe juzgar a nadie sin oírlo y sin darle los medios adecuados para su defensa, en un plano de igualdad de oportunidades y derechos con el demandante, y el que niega el derecho a hacerse justicia por sí mismo.

Teniendo claros estos conceptos, el inciso 1 del artículo 39 de nuestra Ley de Arbitraje, establece cuáles son los requisitos que deben contener en el fondo, tanto la demanda como la contestación.

Así, la demanda debe contener todas las pretensiones objeto de reclamo por parte del demandante en el proceso; y la contestación debe pronunciarse sobre todas aquellas pretensiones. En este último supuesto, es verdad que el demandado podría guardar silencio, caso en el cual el tribunal deberá analizar qué implicancias tendrá esa abstención.

Cabe señalar que dentro del plazo para poder contestar la demanda, también se puede reconvenir. La práctica arbitral nos dice que por lo general estos plazos son de diez días, pero es perfectamente posible que las partes y los tribunales arbitrales establezcan plazos menores o plazos mayores, de acuerdo a la conveniencia del caso concreto.

Sobre la reconvención, Monroy Gálvez ${ }^{9}$ señala que sin duda se trata del ejercicio del derecho de acción (ya explicado anteriormente) por parte del demandado, razón por la cual este hecho sólo puede ocurrir en un proceso ya iniciado, en el que éste ha sido emplazado. Por tal mérito, el demandado incorpora al proceso una pretensión propia, absolutamente autónoma respecto de la pretensión contenida en la demanda, la que además está dirigida contra el demandante.

Cabe distinguir la reconvención de la contrademanda. En palabras de Monroy, ésta es la especie del género que es la reconvención. En efecto, la contrademanda es la pretensión intentada por el demandado dentro del mismo proceso, caracterizada porque guarda

Cfr. Chovenda, Giuseppe. Instituciones de Derecho Procesal Civil. Madrid: Revista de Derecho Privado, 1954, tomo I, p. 183.

Cfr. González Pérez, Jesús. El derecho a la tutela jurisdiccional. Madrid: Civitas, 1984, pp. 98 y 99.

Cfr. Devis Echeandía, Hernando. Nociones generales de Derecho Procesal. Madrid: Aguilar, 1966, p. 208.

Cfr. Monroy Gálvez, Juan. Teoría general del proceso. Op. cit., pp. 512 y ss. 
conexidad con la pretensión principal. Es decir, en la contrademanda la pretensión intentada por el demandado-reconviniente debe estar fáctica y jurídicamente relacionada con la pretensión del demandante. Así, por ejemplo, si una persona demanda a otra el perfeccionamiento de un contrato de compraventa, habrá contrademanda si el demandado pretende la resolución del contrato. En suma, aquello que se da en llamar contrademanda se debe nombrar, en estricto, contrapretensión, dado que están conectados los hechos y el derecho que configuran las pretensiones del demandante y el demandado, en tanto la de este último se opone directamente a la del primero.

De otro lado, también resulta importante destacar la diferencia, expuesta por Monroy, que existe entre la reconvención y el ejercicio del derecho de defensa por parte del demandado, sobre todo porque suelen confundirse, ya que regularmente se ejercen en el mismo plazo y a veces conjuntamente. Al usarse una defensa de fondo, el demandado contradice la pretensión dirigida contra él, discutiendo y contraprobando los hechos alegados por el demandante. Lo más exitoso que le podría ocurrir a un demandado que usa una defensa de fondo es que se declare infundada la pretensión $y$, en consecuencia, quede liberado de su cumplimiento. En cambio, en el caso de la reconvención, el demandado puede conseguir, si la reconvención es declarada fundada, vincular al demandante a la ejecución de la pretensión contenida en la reconvención.

\section{LOS MEDIOS PROBATORIOS}

El inciso 2 del artículo 39 de la Ley de Arbitraje señala que las partes, al plantear su demanda y contestación, deberán aportar todos los documentos que consideren pertinentes o hacer referencia a los documentos u otras pruebas que vayan a presentar o proponer.

Creemos que el contenido de este inciso debió ser más claro y es que debieron utilizarse términos procesales más exactos. De lo que se trata es de que las partes deben ofrecer, tanto en la demanda como en la contestación o reconvención, todos los medios probatorios que consideren convenientes, es decir, con independencia de que sean medios probatorios de actuación inmediata, o sean medios probatorios cuya actuación deberá realizarse dentro de la etapa probatoria del proceso (como declaración de testigos, declaración de partes, inspecciones arbitrales, etc.).

En ese sentido, debió emplearse un lenguaje jurídico más preciso que el utilizado en el inciso 2 del artículo 39 de la Ley de Arbitraje.
Por otro lado, se dice que se debe aportar todos los documentos probatorios en el proceso o hacer referencia a los documentos u otras pruebas que «se vayan» a presentar o proponer.

Esto resulta un contrasentido, ya que no se puede presentar ni proponer nada en el futuro. El ofrecimiento de pruebas se realiza con la demanda o con la contestación de la demanda y reconvención. Es decir, no hay un segundo «momento oportuno» para poder ofrecer medios probatorios. La única posibilidad que el Derecho Procesal ${ }^{10}$ contempla al respecto, es aquélla en la cual se trate de medios probatorios relativos a hechos nuevos.

La razón de la adopción de esta postura es la de promover la buena fe y la lealtad en el proceso, aspectos que se verían vulnerados si es que se permitiese que alguna parte pueda ofrecer medios probatorios en cualquier momento. Así, pues, teniendo claro que los medios probatorios deben ser ofrecidos por las partes en los actos postulatorios (demanda y contestación), la única excepción a esta regla sería que estemos ante hechos nuevos. De lo contrario, el proceso arbitral sería caótico.

Hecho nuevo es todo acontecimiento que llega a conocimiento de las partes después de trabada la relación procesal y que

10 Somos de la opinión de que el arbitraje constituye una figura autónoma e independiente respecto a otras ramas del Derecho (en este caso específico, nos referimos al Derecho Procesal Civil). Sin embargo, ello no quita que su desarrollo se pueda nutrir de contenidos e instituciones propios de estas materias. En ese sentido, y sólo como una referencia legislativa, cabe citar lo estipulado por el artículo 429 del Código Procesal Civil:

Artículo 429.- «Medios probatorios extemporáneos

Después de interpuesta la demanda, sólo pueden ser ofrecidos los medios probatorios referidos a hechos nuevos y a los mencionados por la otra parte al contestar la demanda o reconvenir.

$[\ldots] . »$ 
debe hallarse encuadrado en los términos de la causa y objeto de la pretensión deducida en el proceso. Con ello se evita cercenar injustificadamente el derecho de defensa de las partes y porque el fin de todo proceso es resolver el conflicto que lo motiva, razón por la cual todas las cuestiones relacionadas con ese conflicto deben ser susceptibles de invocarse con anterioridad al pronunciamiento final. Ledesma Narváez llama a este hecho «un caso de integración de la pretensión», pues sin alterar ninguno de los elementos de ésta (sujeto, objeto y causa), se incorporan al proceso una o más circunstancias de hecho tendientes a confirmar o complementar la causa petendi. Por ello se debe destacar que los hechos nuevos no sólo deben tener relación con la causa controvertida, sino que además deben hallarse encuadrados dentro de los términos de la causa y el objeto de la pretensión, ya que, de lo contrario, ésta no resultaría integrada sino transformada. ${ }^{11}$

Ahora bien, como es lógico, esos medios probatorios sobre hechos nuevos no podrán ser ofrecidos con la demanda, con la contestación de la demanda o la reconvención, en la medida en que no se conoce su existencia, por cuanto todavía no han ocurrido o, peor aún, no ocurrirán en el futuro.

Si se hiciera mención en la demanda, contestación o reconvención, a esos futuros medios probatorios, sin duda no se tratará de un hecho nuevo, sino más bien de un hecho inexisten- te. De otro lado, si se trata de un hecho futuro, cuya producción todavía no ha ocurrido, podría hacerse referencia al mismo, pero esto sería especular, razón por la cual en realidad creemos que el momento oportuno para ofrecer el medio probatorio sería cuando en realidad éste se haya producido. Nadie es, pues, dueño del futuro.

Por todas estas consideraciones, creemos que el inciso 2 del artículo 39 de la Ley de Arbitraje contiene serios defectos de orden procesal.

\section{MODIFICACIÓN DE LA DEMANDA Y LA CONTESTACIÓN}

El inciso 3 del artículo 39 de la Ley de Arbitraje señala que salvo acuerdo en contrario, en el curso de las actuaciones, cualquiera de las partes podrá modificar o ampliar su demanda o contestación, a menos que el tribunal arbitral considere que no corresponde permitir esa modificación en razón de la demora con que se hubiere hecho, el perjuicio que pudiera causar a la otra parte o cualesquiera otras circunstancias. El contenido de la modificación y de la ampliación de la demanda o contestación, deberán estar incluidos dentro de los alcances del convenio arbitral.

Creemos que la reflexión que cabría formular, es que cualquier modificación o ampliación de demanda plantea, necesariamente, una dilación al proceso arbitral, a menos que tales variaciones sean formuladas de inmediato, acto seguido de interpuesta la demanda y antes de que el tribunal corra traslado de ella a la parte contraria.

En todos los demás casos, la modificación o ampliación de demanda representará una dilación en los plazos procesales.

Queda claro además que cuando la ampliación o modificación de demanda se produzca en plena etapa probatoria, ella puede tener un impacto importante en los términos o plazos del arbitraje, pues podría obligar a actuar una serie de medios probatorios adicionales, los mismos que podrían incluir -por ejemplo- la realización de nuevas pericias o nuevas inspecciones arbitrales en adición a las ya realizadas.

En ese orden de ideas, creemos que sólo tendría sentido que los tribunales acepten estas modificaciones o ampliaciones de demanda, dentro de la etapa probatoria, cuando se trate de pretensiones que vengan acompañadas de medios probatorios de ejecución inmediata o, si se hubiesen ofrecido pericias, declaraciones de parte, declaraciones de testigos o inspecciones arbitrales, antes de que el Tribunal Arbitral haya dispuesto la actuación de los medios probatorios ofrecidos en la demanda original.

Caso contrario, aceptar la ampliación de pretensiones implicaría una distorsión en los términos que naturalmente debe guardar un proceso arbitral.

Sin embargo, hay que reconocer que con la ampliación de pretensiones, en el fondo las partes pueden estar ganando

11 Cfr. Ledesma Narváez, Marianella. Comentarios al Código Procesal Civil. Análisis artículo por artículo. $4^{\text {a }}$ Edición. Lima: Gaceta Jurídica, 2012, tomo I, pp. 930 y 931. 
tiempo, no con respecto al propio proceso en el que se solicita dicha ampliación, sino en lo que respecta a ahorrarse el inicio de un nuevo proceso arbitral, cuya instalación, sin duda, demorará algún tiempo.

Asimismo, cabe señalar que el inicio de otro u otros procesos arbitrales acarrearía el riesgo de que la conformación de los tribunales arbitrales no coincida en cuanto a sus integrantes, lo que podría conducir a decisiones en alguna medida contradictorias.

De otra parte, resulta importante tener en cuenta que la norma también se refiere al hecho de que se debe tener en consideración el perjuicio que se pudiera causar a la otra parte.

Rodríguez Merino ${ }^{12}$ señala que la cuestión no deja de ser sumamente delicada, ya que puede constituirse en fuente de conflictos. La ampliación de hechos o modificación de campo de demanda y contestación puede implicar necesariamente la práctica de medios de prueba y la consiguiente demora en el desarrollo del procedimiento.

Finalmente, el inciso 3 del artículo 39, culmina señalando que el contenido de la modificación y de la ampliación de la demanda o contestación, deberán estar incluidos dentro de los alcances del convenio arbitral, porque, de lo contrario, el tribunal arbitral sería incompetente, y si se procediese de manera distinta, la parte perjudicada podrá deducir sobre estas modificaciones o ampliaciones de las pretensiones una excepción de incompetencia.

\section{CONSOLIDACIÓN DE DOS O MÁS ARBITRAJES}

Finalmente, el inciso 4 del artículo 39 de la Ley de Arbitraje señala que salvo pacto en contrario, el tribunal arbitral no puede disponer la consolidación de dos o más arbitrajes, o disponer la realización de audiencias conjuntas.

El numeral citado resulta claro, y es, como se puede observar, de carácter meramente dispositivo.

Sin embargo, creemos importante esbozar algunos comentarios sobre el concepto de acumulación.

Así, se sabe que la acumulación de procesos es la reunión de distintas acciones ya iniciadas en distintos procesos, para que se continúen en un solo expediente y se decidan a través de un solo fallo. El fundamento de esta figura es el principio de economía procesal y el interés de que no se dicten sentencias o laudos contradictorios.
Por otro lado, y teniendo en cuenta que proceder de esta manera es perfectamente posible, Viale Salazar ${ }^{13}$ identifica algunos problemas que se podrían presentar, los cuales se encuentran referidos, principalmente, a los sujetos que intervienen en cada uno de los arbitrajes a consolidar, la conformación del tribunal arbitral que debe continuar con un caso consolidado, la posible vulneración del principio de confidencialidad del arbitraje cuando se trata de arbitrajes en donde no coinciden exactamente las mismas partes, entre otros.

Creemos que la aplicación de esta figura en sede arbitral debe aplicarse con suma cautela.

Sin perjuicio de lo señalado, reiteramos la postura en el sentido de que proceder de esta manera es perfectamente posible, pues el contenido del inciso 4 del artículo 39 de la Ley de Arbitraje no es uno de carácter imperativo.

\section{Comentario final}

Creemos que, sin perjuicio de las ideas esbozadas en este breve estudio, mucho dependerá de cómo es que el tribunal arbitral vaya a actuar en cada caso que se le presente y es que las figuras estudiadas constituyen temas debatibles.

12 Cfr. Rodríguez Merino, Abelardo. «Demanda y contestación». En Comentarios prácticos a la Ley de Arbitraje. Valladolid: Editorial Lex Nova, 2004, pp. 513 y 514.

13 Cfr. Viale Salazar, Fausto. «Demanda y contestación». En Comentarios a la ley peruana de arbitraje. Lima: Instituto Peruano de Arbitraje, 2011, tomo I, p. 454. 